\title{
Comparative study of functional properties of eight walnut (Juglans regia $\mathrm{L}$.) genotypes
}

\author{
İnci CERİT ${ }^{1}$, Ayşe SARIÇAM ${ }^{1}$, Omca DEMİRKOL ${ }^{1 \star}$, Hülya ÜNVER ${ }^{2}$, Ebru SAKAR $^{3}$, Serap COŞANSU ${ }^{1}$
}

\begin{abstract}
Eight walnut (Juglans regia L.) genotypes were assessed for the glutathione (GSH) and total phenolic contents (TPC), as well as their antioxidant capacities. The GSH contents were between 1.1 and $7.2 \mathrm{mg} 100 \mathrm{~g}^{-1}$. The TPC contents ranged from 33 to $50.3 \mathrm{mg} \mathrm{GAE} \mathrm{g}^{-1}$, while the ferric ion reducing antioxidant power (FRAP) values ranged from 156 to $302 \mathrm{mg} \mathrm{FeSO}_{4} \mathrm{~g}^{-1}$. A strong correlation $\left(r^{2}=0.8258\right)$ was determined between the FRAP values and the TPC. Cupric ion reducing antioxidant capacity (CUPRAC) values ranged from 13 to $35 \mathrm{mg}$ trolox $\mathrm{g}^{-1}$. The correlation between the CUPRAC values and the GSH contents was weak $\left(r^{2}=0.2069\right)$. The walnut extracts $\left(0.2 \mathrm{mg} \mathrm{mL}^{-1}\right.$ concentration) showed $16.2-40 \% \mathrm{DPPH}$ (2,2-diphenyl-1-picrylhydrazyl) scavenging activity. A strong correlation between DPPH-TPC was determined $\left(r^{2}=0.8538\right)$, and it was concluded that the TPC makes the most important contribution to the antioxidant capacity of the walnut. Additionally, the walnut may be appraised, in view of its nutritional value and health benefits, by considering the GSH content revealed in the current study.
\end{abstract}

Keywords: walnut; Juglans regia L.; glutathione; total phenolic compounds; antioxidant activity.

Practical Application: Walnuts (Juglans regia L.) have higher antioxidant activity than the other nut species. The main emphasis of this study is to focus on contents of GSH and TPC as well as antioxidant activity. To our knowledge, this is the first study assesses antioxidant properties of walnut with different aspects including GSH and TPC as well as FRAP, CUPRAC and DPPH scavenging activity values that presents both the GSH content and the antioxidant capacity properties of walnuts.

\section{Introduction}

A natural, balanced, and high quality diet has become a considerable issue in recent years. Therefore, epidemiological studies focus on functional foods that are described as not only supplying the basic nutritional ingredients, but also as influencing treatments and protection against illness. The walnut (Juglans regia L.) is a functional food that contains appropriate portion of basic nutritional elements and plays an important role as a promoter of medicine used for heart diseases (Bakkalbaşı et al., 2012).

Fruits, vegetables, and grain products are natural sources of antioxidants that help decrease the adverse effects of free radicals on the body. Damages caused by free radicals, like DNA mutation, cross-linking of proteins, and lipid peroxidation, are inhibited by antioxidants. Because of this effect, antioxidant compounds in foods have significant role to prevent chronic diseases such as cancer or heart disease. Walnuts contain important antioxidants that are mainly tocopherols and phenolic compounds (Kornsteiner et al., 2006; Pereira et al., 2008). The anti-inflammation and antioxidant properties of phenolic compounds in plants correlate with a reduction in the risk of several diseases. For example, it has been shown that walnuts are a source of polyphenolics (like ellagic acid and gallic acids) and inhibit in vitro plasma and LDL oxidation (Anderson et al., 2001; Chen \& Blumberg, 2008).

Thiols, characterized as mercaptan, are other important antioxidants and they figure on protein synthesis. Fresh fruits, vegetables, and some spices contain high amounts of thiols like glutathione, cysteine, homocysteine and captopril. The most prominent thiol, glutathione ( $\gamma$-L-glutamyl-L-cysteinyl-glycine, GSH), protects cells from oxidative damage. Unfortunately, there are only limited number of research that measure the thiol levels in foods (Demirkol et al., 2004; Gümüşay et al., 2015).

As a natural reservoir reducing power, GSH can be quickly used by cells against oxidative stress. The hydrogen in its sulfhydryl group shows antioxidant activity by reducing molecules that are under oxidative stress. Since a lack of GSH places cells at risk of oxidative damage, the instability of GSH levels observed during neurodegenerative diseases, cancer, HIV, and ageing, is not a surprise. GSH, that shows activity as an electron donor in reduction reactions, is effective in removing reactive oxygen species (ROS) such as free radicals, lipid peroxyl radicals, hydroxyl radicals, peroxy nitrite, and hydrogen peroxide (Demirkol \& Ercal, 2011). Several studies have revealed that thiols play a significant role in preventing damage (especially apoptosis) caused by ROS; oxidative stress induces apoptosis and necrosis in cases of GSH deficiency (Higuchi, 2004). GSH has a significant role in detoxification of harmful substances such as toxins, metals, herbicides, and xenobiotics, making conjugates with them. It is vitally important in protecting the intestines against oxidative damage and toxic substances from foods (Demirkol \& Ercal, 2011). 
Walnuts are a rich source of polyunsaturated fatty acids (PUFA), mainly linolenic and linoleic acids. The high PUFA content of walnuts (72.6-78.0\% of total fatty acids) reduces the risk of heart disease by increasing the HDL cholesterol and decreasing the LDL cholesterol. In addition, walnuts contain

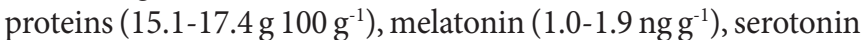
(10-34 $\left.\mathrm{ng} \mathrm{g}^{-1}\right)$, minerals [potassium (300-370 mg $\left.100 \mathrm{~g}^{-1}\right)$, calcium

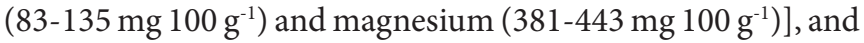

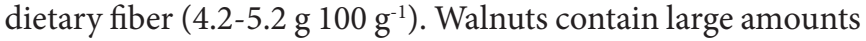
of proteins with a dry basis that are digestible and valuable in human nutrition, especially for vegetarians. Because of all of these compounds, the walnut has high potential as a functional food for human consumption. However, genetics, harvest time, origin of the foods, soil quality, environmental factors, processing, and storage conditions influence the composition and functionality of walnuts (Savage, 2001; Tapia et al., 2013).

In the literature, there is limited research on GSH content of walnuts and it is believed that the research that reveals genotypic differences of walnuts will be a good source for researchers. Therefore, the purpose of the study was to detect the GSH, total phenolic contents and antioxidant capacity of eight walnut genotypes grown in Turkey. For that, the antioxidant potential of walnuts was specified spectrophotometrically by TPC, DPPH scavenging activity, FRAP, and CUPRAC. In addition, the glutathione contents were determined quantitatively by High Performance Liquid Chromatography (HPLC).

\section{Materials and methods}

\subsection{Reagents and chemicals}

Acetonitrile, methanol (HPLC grades), sodium carbonate, gallic acid, hydrochloric acid, ferric chloride hexahydrate and sodium acetate trihydrate (all analytical grades) were provided from Merck (Darmstadt, Germany). Acetic acid, phosphoric acid and borate were purchased from Fisher (St. Louis, MO). All other chemicals were supplied from Sigma (St. Louis, MO).

\subsection{Plant Material}

Eight walnut (Juglans regia L.) genotypes (18ÇKR09, 18ÇKR64, 18ÇKR37, 18ÇKR28, 18ÇKR23, 18ÇKR20, 18ÇKR35, 18ÇKR31) selected in a previous study (Ünver et al., 2015) were used. All walnut samples were harvested in 2013 from selected settlements (Çerkeş, Korgun, Yapraklı Eldivan and Bayramören) of Çankırı province in Turkey. Walnut samples were dried on paper sheets at an ambient temperature, after removing the outer green skin, and then dried in an oven at $25^{\circ} \mathrm{C}$ for 24 hours. All walnut samples were kept in a refrigerator until analyzed. The hard shells of the samples were cracked and peeled manually, and then the nuts were milled (Premier PRG-259, South Korea). Oil was removed by a soxhelet extractor using petroleum ether.

\subsection{Extraction of samples for GSH content}

To prepare the walnut extracts, the procedure described by Demirkol et al. (2004) was followed. The concentration of $0.1 \mathrm{~g} \mathrm{~mL}^{-1}$ was used in the extraction of samples.

\subsection{GSH determination by the HPLC method}

The GSH amount of the samples were detected with the method that was developed by Winters et al. (1995) and modified by Demirkol et al. (2004). The HPLC system (Hitachi, Tokyo, Japan) was comprised of an injection valve with a $5 \mu \mathrm{L}$ injection filling loop and a fluorescence detector (emission and excitation wavelengths at $376 \mathrm{~nm}$ and $330 \mathrm{~nm}$, respectively). Reliasil ODS-1 C18 column (reversed-phase, $5 \mu \mathrm{m}, 250 \times 4.6 \mathrm{~mm}$, Orochem, Naperville, USA) was used to separation. Calibration curves were obtained for 0 to $2500 \mathrm{nM}$ GSH concentrations $\left(r^{2}=0.9975\right)$.

\subsection{Extraction of samples for TPC, FRAP, and DPPH}

Five mL methanol: water (70:30) solution was added to each de-oiled and powdered walnut sample $(50 \mathrm{mg})$. After keeping the tubes in an ultrasonic water bath for $15 \mathrm{~min}$, they were centrifuged at $13,130 \times g$ for $10 \mathrm{~min}$ at $4{ }^{\circ} \mathrm{C}$ (Wojdyło et al., 2007).

\subsection{Determination of TPC}

The amounts of TPC were detected with the method developed by Gao et al. (2000) and modified by Gümüşay et al. (2015). Calibration curve was obtained with gallic acid at different concentrations $\left(r^{2}=0.9934\right)$.

\subsection{FRAP assay}

FRAP assay was applied according to Benzie \& Strain (1996) with some modifications. The FRAP reactive was composed of acetate buffer ( $300 \mathrm{mM}, \mathrm{pH} 3.6)$, TPTZ (10 mM) and $\mathrm{FeCl}_{3}(20 \mathrm{mM})$ as a ratio of $10: 1: 1$, respectively and kept at $37^{\circ} \mathrm{C}$. One hundred $\mu \mathrm{L}$ of the walnut extracts, $1.8 \mathrm{~mL}$ of FRAP reactive and $1.2 \mathrm{~mL}$ of distilled water were transferred to tubes and the mixture was kept at $37^{\circ} \mathrm{C}$ for $15 \mathrm{~min}$. The absorbance of the resulting solution was determined in $593 \mathrm{~nm}$ wavelength (Shimadzu UV-1240). Calibration curve was obtained with $\mathrm{FeSO}_{4}$ at different concentrations $\left(r^{2}=0.9902\right)$.

\subsection{Extraction of samples for CUPRAC}

The method described by Capanoglu et al. (2008) and modified by Gümüşay et al. (2015) was performed to extraction of samples.

\subsection{CUPRAC assay}

The method developed by Apak et al. (2008) was used to CUPRAC assay. Calibration curve was obtained with trolox at different concentrations $\left(r^{2}=0.9964\right)$.

\subsection{DPPH radical scavenging capacity assay}

The walnut extracts were diluted to a $0.2 \mathrm{mg} \mathrm{mL}^{-1}$ concentration. Two hundred $\mu \mathrm{L}$ of the diluted extract and $3 \mathrm{~mL}$ of DPPH solution were mixed in a tube. The mixture was stirred and hold in the dark for $30 \mathrm{~min}$. Absorbance was determined at $517 \mathrm{~nm}$ (Shimadzu UV-1240). The results was subsequently 
calculated according to the following equation: $\mathrm{DPPH}$ radical scavenging capacity $(\%)=\left[\left(\mathrm{A}_{0}-\mathrm{A}_{1}\right) / \mathrm{A}_{0}\right] \times 100$, where $\mathrm{A}_{0}$ is absorbance of the blank (mixture with methanol instead of sample) and, $A_{1}$ is absorbance of reacting mixture with the test sample (Brand-Williams et al., 1995).

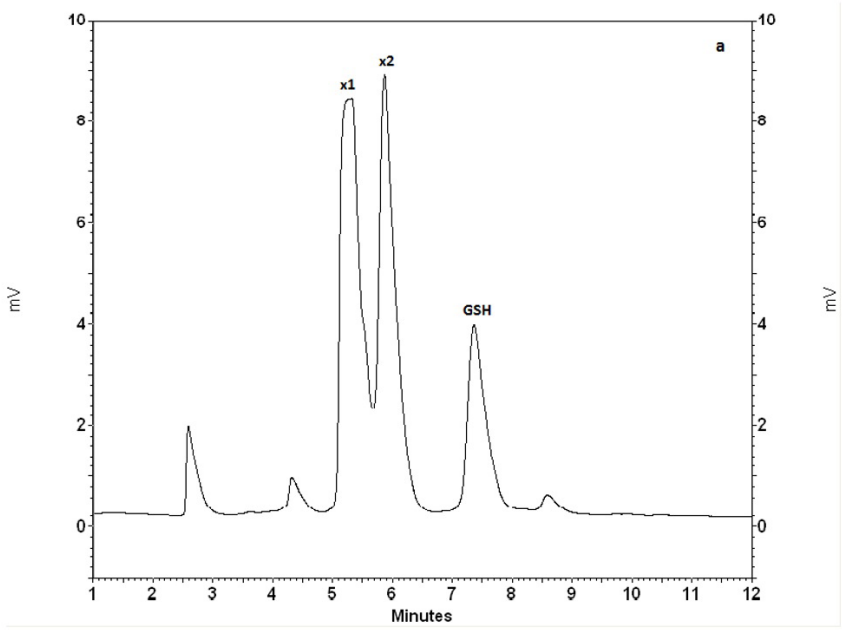

(a)

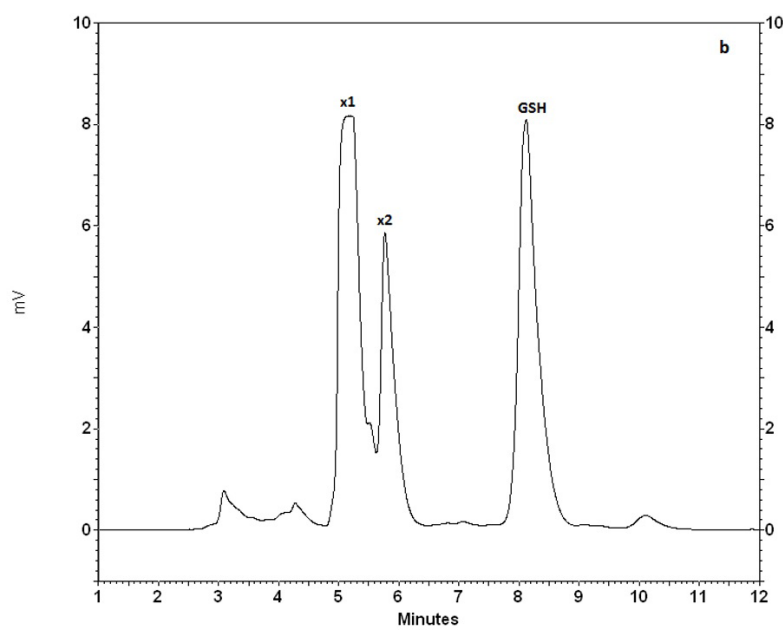

(b)

Figure 1. Chromatogram of NPM-derivatized standard (a) and walnut sample (b) showing GSH, X1, X2 representing NPM hydrolysis peaks.

\subsection{Statistical analysis}

All analyses were done in triplicate $(n=3)$. Results were subjected to ANOVA using SPSS 20.0 for Windows (SPSS, Chicago, IL). Duncan's multiple range test was used at $5 \%$ level of significance using one-way analysis of variance (ANOVA).

\section{Results and discussion}

A rapid separation and identification of GSH in the HPLC system were provided by means of the NPM-GSH structure obtained through derivatization of the walnut extracts with NPM (Demirkol et al., 2004). Figure 1 shows the HPLC chromatogram of a walnut sample that was derivatized by NPM. According to the HPLC chromatograms of the sample extracts, it was revealed that only GSH was in the walnut, and that the other biological thiols like captopril, cysteine and homocysteine were not.

The GSH contents of the walnut samples changed from

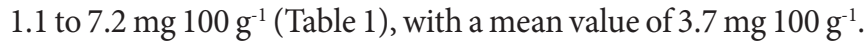
Literature data on the GSH contents of walnuts and dried nuts are limited. The GSH content of a walnut was reported

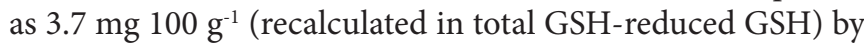
Jones et al. (1992), which is similar to the mean value obtained in the current study. Interestingly, the GSH contents of the walnut samples taken from trees estimated to be $28-35$ years old were remarkably lower than those obtained from trees estimated to be $18-20$ years old (Figure 2 ).

Although numerous studies were conducted in vivo or in vitro on synthesis and functions of GSH, there is limited research on the GSH content of food. The GSH content of some vegetables like asparagus, green beans, spinach were determined as 349,230 and $313 \mathrm{nM} \mathrm{g}^{-1}$ wet weight, respectively (Demirkol et al., 2004). It was also reported that GSH content of fruits like strawberry, watermelon and oranges as $6.9,5.0$ and $4.8 \mathrm{mg} 100 \mathrm{~g}^{-1}$ wet weight, respectively (Jones et al., 1992). The GSH content is affected by such factors as growing conditions of plants, plant species, seasonal and geographical differences, storage, conditions during processing and preparation of food. For instance, GSH is readily oxidized during processing, storage, and preparation. Moreover, its concentration may be reduced even after food is digested because many foods contain reactive elecrophile compounds. Frozen foods may contain GSH in as high amounts as fresh food does; however, drying, cooking, canning, and disinfectants used by the food industry can cause a significant loss

Table 1. GSH content, TPC, FRAP, CUPRAC, and DPPH radical scavenging activity results for eight walnut genotypes $(\mathrm{mean} \pm \mathrm{SD}, \mathrm{n}=3)$.

\begin{tabular}{|c|c|c|c|c|c|}
\hline Walnut Cultivar & $\mathrm{GSH}\left(\mathrm{mg} 100 \mathrm{~g}^{-1}\right)$ & TPC (mg GAE g $\left.{ }^{-1}\right)$ & FRAP $\left(\mathrm{mg} \mathrm{FeSO}_{4} \mathrm{~g}^{-1}\right)$ & CUPRAC $\left(\mathrm{mg}\right.$ trolox $\left.\mathrm{g}^{-1}\right)$ & DPPH (\%) \\
\hline 18ÇKR09 & $1.5 \pm 0.1^{B}$ & $35.4 \pm 0.7^{A}$ & $195 \pm 12^{B}$ & $19 \pm 3^{B}$ & $27 \pm 1^{C}$ \\
\hline 18ÇKR20 & $7.2 \pm 0.2^{F}$ & $33.5 \pm 1.6^{A}$ & $156 \pm 12^{A}$ & $20 \pm 2^{B}$ & $21 \pm 1^{B}$ \\
\hline 18ÇKR23 & $1.6 \pm 0.1^{B}$ & $44.2 \pm 0.6^{C}$ & $261 \pm 14^{D E}$ & $29.5 \pm 0.7^{C}$ & $35 \pm 1^{D}$ \\
\hline 18ÇKR28 & $2.1 \pm 0.2^{C}$ & $46.4 \pm 6.7^{C D}$ & $284 \pm 20^{E F}$ & $35 \pm 2^{D}$ & $40 \pm 1^{E}$ \\
\hline 18ÇKR31 & $4.4 \pm 0.0^{D}$ & $50.3 \pm 0.7^{E}$ & $302 \pm 12^{F}$ & $28.8 \pm 0.3^{C}$ & $40 \pm 1^{E}$ \\
\hline 18ÇKR35 & $4.9 \pm 0.0^{E}$ & $49.1 \pm 0.1^{D E}$ & $238 \pm 0.6^{C D}$ & $20 \pm 3^{B}$ & $36 \pm 1^{D}$ \\
\hline 18ÇKR37 & $1.1 \pm 0.1^{A}$ & $38.3 \pm 1.4^{B}$ & $208 \pm 18^{B C}$ & $19.8 \pm 0.6^{B}$ & $30 \pm 2^{C}$ \\
\hline 18ÇKR64 & $7.11 \pm 0.27^{F}$ & $34 \pm 1^{A}$ & $186 \pm 14^{A B}$ & $13 \pm 3^{A}$ & $16.2 \pm 0.3^{A}$ \\
\hline
\end{tabular}

${ }^{A-F}$ Any two means in the same column having different letters are significantly different $(\mathrm{P}<0.05)$. 


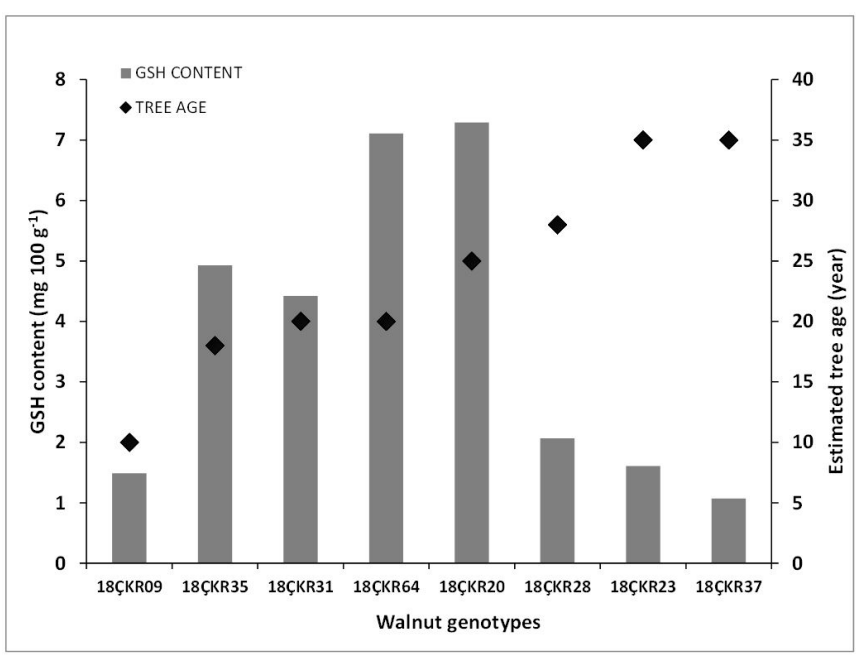

Figure 2. Relation between GSH content and estimated tree age.

Table 2. Correlation between antioxidant content and antioxidant activity.

\begin{tabular}{lc}
\hline Correlation & $r^{2}$ \\
\hline TPC vs. FRAP & 0.8258 \\
TPC vs. DPPH & 0.8538 \\
TPC vs. CUPRAC & 0.4900 \\
GSH vs. FRAP & 0.1644 \\
GSH vs. DPPH & 0.3035 \\
GSH vs. CUPRAC & 0.2069 \\
\hline
\end{tabular}

of GSH (Demirkol et al., 2004; Gümüşay et al., 2015; Jones et al., 1992; Qiang et al., 2005). Therefore, the incidence of GSH in a food, such as a walnut (which has a hard shell), is important in view of its bioavailability. This hard shell is believed to more readily preserve the walnut's edible part against oxidation, than the skins of other fruits and vegetables do. Additionally, a walnut has the advantage of the bioavailability of GSH because it can be consumed without any processing after harvesting. McKay et al. (2010) reported an increase in the total thiol level in the plasmas of healthy adults (over age 21) who consumed $42 \mathrm{~g}$ of a walnut. This finding may be considered an indication of the bioavailability of GSH in a walnut.

Walnuts are rich in phenolic compounds and have higher TPC than other nuts (Kornsteiner et al., 2006; Reddy et al., 2010). The total phenolic contents of eight walnut cultivars were between 33 and $50.3 \mathrm{mg} \mathrm{GAE} \mathrm{g}^{-1}$ (Table 1). Tapia et al. (2013) indicated that the highest TPC of a walnut was $58 \mathrm{mg} \mathrm{GAE} \mathrm{g}^{-1}$ fresh weight. In another study, the TPC of the walnut samples were determined to be $58.8-95.1 \mathrm{mg} \mathrm{GAE} \mathrm{g}^{-1}$ by Pereira et al. (2008) and 3.3-31.8 $\mathrm{mg} \mathrm{GAE} \mathrm{g}^{-1}$ (recalculated) by Bakkalbaşı et al. (2012). The differences between the TPC of the walnut samples may have been due to climatic differences, storage conditions, the harvesting year, or variety, as well as the differences between the cultivars. Especially, pre- and post-harvest factors significantly affected the TPC, polyphenol content, and total antioxidant capacities of a group of nuts, including walnuts (Bolling et al., 2011). Additionally, the distinctiveness of extraction procedures in the methods used for TPC analyses may have been another reason for these differences.
Phenolic compounds, which impact both the sensory properties and the bioavailability of plant foods, are significant bioactive compounds of walnuts. They have become very popular recently, in view of their relationship with nutrition and health. A fistful of crushed walnuts have much more phenolic compound than do a milky chocolate bar, a glass of red wine and apple juice (Anderson et al., 2001). The contribution of phenolic compounds and a fatty acid profile, identified by related studies, revealed that the consumption of walnuts reduces LDL cholesterol oxidation and plasma lipid peroxidation and, remarkably, causes increases in plasma antioxidant capacity (Anderson et al., 2001; Griel \& Kris-Etherton, 2006). Tapia et al. (2013) have emphasized the correlation between the PUFA/ $\alpha$-linolenic acid contents and the TPC of walnut cultivars. However, considering the fatty acid contents of the same walnut cultivars (as determined in a previous study by Ünver et al., 2015) and the TPC determined in the current study, such a correlation could not be determined.

The FRAP assay was developed to determine the $\mathrm{Fe}^{+3}$ reducing ability of compounds. The FRAP values of the walnut samples ranged from 156-302 $\mathrm{mg} \mathrm{FeSO}_{4} \mathrm{~g}^{-1}$ (Table 1). Christopoulos \& Tsantili (2011) was reported that initial FRAP values of three walnut cultivars were 153.4, 181.2 and $95.4 \mu \mathrm{mol}$ trolox acid equivalent $\mathrm{g}^{-1}$ dry matter. The differences in FRAP values among cultivars were significant that is similar to results of this study. The lowest FRAP value was determined in sample 18ÇKR20, which had the lowest TPC. Correspondingly, the highest FRAP value was displayed in sample $18 C ̧ K R 31$, which also had the highest TPC. There was a strong correlation $\left(r^{2}=0.8258\right)$ between the TPC and FRAP values of eight walnut cultivars (Table 2). Likewise, Reddy et al. (2010) reported a significant correlation as $r^{2}=75.64$ (\%) between the total phenolic contents and FRAP values of dry nuts, including walnuts.

In the CUPRAC method, which is recommended to measure the antioxidant activity of specific compounds such as GSH, Cys and $\mathrm{HCys}$ carrying $-\mathrm{SH}$ functional group, the cupric neocuprine complex $[\mathrm{Cu}(\mathrm{II})-\mathrm{Nc}]$ reacts with the functional group of the antioxidant. It then generates the cuprous form $[\mathrm{Cu}(\mathrm{I})-\mathrm{Nc}]$ and displays a maximum light absorption of $450 \mathrm{~nm}$ (Güngör et al., 2011). Güngör et al. (2011) compared the methods used to determine antioxidant activities of thiol based antioxidants and concluded that the most proper method for thiols was CUPRAC. They also concluded that the results obtained by the FRAP method were not consistent, even in the samples with a high GSH content. The CUPRAC reactive was fast enough to oxidize the thiol types antioxidants, such as GSH, as well as having the ability to measure hydrophilic and lipolytic antioxidants such as vitamin E (Apak et al., 2004). As shown in Table 1, among the eight walnut cultivars, 18 ÇKR 28 yielded the highest CUPRAC value ( $35 \mathrm{mg}^{\text {trolox g}}{ }^{-1}$ ), while 18 ÇKR64 had the lowest CUPRAC value (13 $\mathrm{mg}$ trolox $\mathrm{g}^{-1}$ ).

In contrast to expectations, the correlation between the GSH contents and the CUPRAC values was weak $\left(r^{2}=0.2069\right)$. This weak correlation could have arisen from the low amount of GSH in the TPC of the walnut samples studied. Similarly, the weak correlation between the total phenolic contents of some plant samples and total antioxidant activity values had been detected previously (Kamiloglu et al., 2014). Additionally, the 
correlations between GSH and FRAP $\left(r^{2}=0.1644\right)$ and between GSH and DPPH $\left(r^{2}=0.3035\right)$ were weak, as expected (Table 2$)$.

The DPPH scavenging activity assay is commonly used to determine the antioxidant potential of plant materials. In the current study, the antiradical activities or hydrogen donating abilities of walnut extracts were measured by the decreases observed in the absorbance of a DPPH radical. As shown in Table 1, the walnut extracts, with $0.2 \mathrm{mg} \mathrm{mL}^{-1}$ concentrations, showed DPPH scavenging activity from 16.2 to $40 \%$. Pereira et al. (2008) reported 90.2-92.6\% DPPH scavenging activity with a $0.5 \mathrm{mg} \mathrm{mL}^{-1}$ concentration. The DPPH scavenging activity of the pellicle and kernel parts of the walnut samples were detected as being $73.3 \%$ and $1.2 \%$, respectively (Akbari et al., 2012). A strong correlation $\left(r^{2}=0.8538\right)$ was determined for DPPH/TPC (Table 2). Correspondingly, a similar correlation was determined by Reddy et al. (2010) between the TPC and DPPH scavenging activity values of dry nut samples.

\section{Conclusion}

Functional properties of eight walnut genotypes grown in Turkey were specified in this study and this is the first report on GSH content of walnut genotypes. Considering the limited studies available on the thiol content of walnuts, the findings obtained in the current study may contribute to literature data. Although detailed investigations are needed, the possible relationship between the age of a walnut tree and the GSH content of its fruit is extremely significant. The low correlation between the CUPRAC and GSH contents may be due to a low amount of GSH in the TPC. Therefore, it may be concluded that the TPC makes the most important contribution to the antioxidant capacity of a walnut. Finally, considering the recent increasing interest in the beneficial effects of consuming nuts on health, the results of this study, that presents both the GSH content and the antioxidant capacity properties of walnuts, may be a noteworthy addition to our current knowledge of the healthy contributions of walnuts.

\section{References}

Akbari, V., Jamei, R., Heidari, R., \& Esfahlan, A. J. (2012). Antiradical activity of different parts of Walnut (Juglans regia L.) fruit as a function of genotype. Food Chemistry, 135(4), 2404-2410. PMid:22980820. http://dx.doi.org/10.1016/j.foodchem.2012.07.030.

Anderson, K. J., Teuber, S. S., Gobeille, A., Cremin, P., Waterhouse, A. L., \& Steinberg, F. M. (2001). Walnut polyphenolics inhibit in vitro human plasma and LDL oxidation. The Journal of Nutrition, 131(11), 2837-2842. PMid:11694605.

Apak, R., Güçlü, K., Özyürek, M., \& Çelik, S. E. (2008). Mechanism of antioxidant capacity assays and the CUPRAC (cupric ion reducing antioxidant capacity) assay. Mikrochimica Acta, 160(4), 413-419. http://dx.doi.org/10.1007/s00604-007-0777-0.

Apak, R., Güçlü, K., Özyürek, M., \& Karademir, S. E. (2004). Novel total antioxidant capacity index for dietary polyphenols and vitamins $\mathrm{C}$ and E, using their cupric ion reducing capability in the presence of neocuproine: CUPRAC method. Journal of Agricultural and Food Chemistry, 52(26), 7970-7981. PMid:15612784. http://dx.doi. org/10.1021/jf048741x.
Bakkalbaşı, E., Yılmaz, Ö. M., Javidipour, I., \& Artık, N. (2012). Effects of packaging materials, storage conditions and variety on oxidative stability of shelled walnuts. LWT - Food Science and Technology, 46(1), 203-209. http://dx.doi.org/10.1016/j.lwt.2011.10.006.

Benzie, I. F. F., \& Strain, J. J. (1996). The ferric reducing ability of plasma (FRAP) as a measure of "Antioxidant Power": The FRAP Assay. Analytical Biochemistry, 239(1), 70-76. PMid:8660627. http:// dx.doi.org/10.1006/abio.1996.0292.

Bolling, B. W., Chen, C. Y. O., McKay, D. L., \& Blumberg, J. B. (2011). Tree nut phytochemicals: composition, antioxidant capacity, bioactivity, impact factors. A systematic review of almonds, Brazils, cashews, hazelnuts, macadamias, pecans, pine nuts, pistachios and walnuts. Nutrition Research Reviews, 24(2), 244-275. PMid:22153059. http:// dx.doi.org/10.1017/S095442241100014X.

Brand-Williams, W., Cuvelier, M., \& Berset, C. (1995). Use of a free radical method to evaluate antioxidant activity. $L W T$ - Food Science and Technology, 28(1), 25-30.

Capanoglu, E., Beekwilder, J., Boyacioglu, D., Hall, R., \& De Vos, R. (2008). Changes in antioxidant and metabolite profiles during production of tomato paste. Journal of Agricultural and Food Chemistry, 56(3), 964-973. PMid:18205308. http://dx.doi.org/10.1021/jf072990e.

Chen, C. Y., \& Blumberg, J. B. (2008). Phytochemical composition of nuts. Asia Pacific Journal of Clinical Nutrition, 17(Suppl 1), 329-332. PMid:18296370.

Christopoulos, M. V., \& Tsantili, E. (2011). Effects of temperature and packaging atmosphere on total antioxidants and colour of walnut (Juglans regia L.) kernels during storage. Scientia Horticulturae, 131, 49-57. http://dx.doi.org/10.1016/j.scienta.2011.09.026.

Demirkol, O., \& Ercal, N. (2011). Glutathione. In L. M. Nollet, \& F. Toldra (Eds.), Handbook of analysis of active compounds in functional food (pp. 936). Boca Raton: CRC Press.

Demirkol, O., Adams, C., \& Ercal, N. (2004). Biologically important thiols in various vegetables and fruits. Journal of Agricultural and Food Chemistry, 52(26), 8151-8154. PMid:15612810. http://dx.doi. org/10.1021/jf040266f.

Gao, X., Ohlander, M., Jeppsson, N., Bjork, L., \& Trajkovski, V. (2000). Changes in antioxidant effects and their relationship to phytonutrients in fruits of sea buckthorn (Hippophaer hamnoides L.) during maturation. Journal of Agricultural and Food Chemistry, 48(5), 1485-1490. PMid:10820047. http://dx.doi.org/10.1021/jf991072g.

Griel, A. E., \& Kris-Etherton, P. M. (2006). Tree nuts and the lipid profile: a review of clinical studies. British Journal of Nutrition, 96(Suppl 2), S68-78. PMid:17125536. http://dx.doi.org/10.1017/BJN20061866.

Gümüşay, Ö. A., Borazan, A. A., Ercal, N., \& Demirkol, O. (2015). Drying effects on the antioxidant properties of tomatoes and ginger. Food Chemistry, 173, 156-162. PMid:25466007. http://dx.doi.org/10.1016/j. foodchem.2014.09.162.

Güngör, N., Özyürek, M., Güçlü, K., Çekiç, S. D., \& Apak, M. R. (2011). Comparative evaluation of antioxidant capacities of thiol-based antioxidants measured by different in vitro methods. Talanta, 83(5), 1650-1658. PMid:21238764. http://dx.doi.org/10.1016/j. talanta.2010.11.048.

Higuchi, Y. (2004). Glutathione depletion-induced chromosomal DNA fragmentation associated with apoptosis and necrosis. Journal of Cellular and Molecular Medicine, 8(4), 455-464. PMid:15601574. http://dx.doi.org/10.1111/j.1582-4934.2004.tb00470.x.

Jones, D. P., Coates, R. J., Flagg, E. W., Eley, J. W., Block, G., Greenberg, R. S., Gunter, E. W., \& Jackson, B. (1992). Glutathione in foods listed in the National Cancer Institute's health habits and history 
food frequency questionnaire. Nutrition and Cancer, 17(1), 57-75. PMid:1574445. http://dx.doi.org/10.1080/01635589209514173.

Kamiloglu, S., Demirci, M., Selen, S., Toydemir, G., Boyacioglu, D., \& Capanoglu, E. (2014). Home processing of tomatoes (Solanum lycopersicum): effects on in vitro bioaccessibility of total lycopene, phenolics, flavonoids, and antioxidant capacity. Journal of the Science of Food and Agriculture, 94(11), 2225-2233. PMid:24375495. http:// dx.doi.org/10.1002/jsfa.6546.

Kornsteiner, M., Wagner, K. H., \& Elmadfa, I. (2006). Tocopherols and total phenolics in 10 different nut types. Food Chemistry, 98(2), 381387. http://dx.doi.org/10.1016/j.foodchem.2005.07.033.

McKay, D. L., Chen, C. O., Yeum, K. J., Matthan, N. R., Lichtenstein, A. H., \& Blumberg, J. B. (2010). Research chronic and acute effects of walnuts on antioxidant capacity and nutritional status in humans: a randomized, cross-over pilot study. Nutrition Journal, 9, 21. PMid:20462428. http://dx.doi.org/10.1186/1475-2891-9-21.

Pereira, J. A., Oliveira, I., Sousa, A., Ferreira, I. C., Bento, A., \& Estevinho, L. (2008). Bioactive properties and chemical composition of six walnut (Juglans regia L.) cultivars. Food and Chemical Toxicology, 46(6), 2103-2111. PMid:18334279. http://dx.doi.org/10.1016/j. fct.2008.02.002.

Qiang, Z., Demirkol, O., Ercal, N., \& Adams, C. (2005). Impact of food disinfection on beneficial biothiol contents in vegetables. Journal of Agricultural and Food Chemistry, 53(25), 9830-9840. PMid:16332139. http://dx.doi.org/10.1021/jf051359f.
Reddy, C. V. K., Sreeramulu, D., \& Raghunath, M. (2010). Antioxidant activity of fresh and dry fruits commonly consumed in India. Food Research International, 43(1), 285-288. http://dx.doi.org/10.1016/j. foodres.2009.10.006.

Savage, G. P. (2001). Chemical composition of walnuts (Juglans regia L.) grown in New Zealand. Plant Foods for Human Nutrition, 56(1), 75-82. PMid:11213171. http://dx.doi.org/10.1023/A:1008175606698.

Tapia, M. I., Sánchez-Morgado, J. R., García-Parra, J., Ramírez, R., Hernández, T., \& González-Gómez, D. (2013). Comparative study of the nutritional and bioactive compounds content of four walnut (Juglans regia L.) cultivars. Journal of Food Composition and Analysis, 31(2), 232-237. http://dx.doi.org/10.1016/j.jfca.2013.06.004.

Ünver, H., Sakar, E., \& Sülüşoğlu, M. (2015). Determination of pomological and morphological characteristics with fatty acid composition of high kernel ratio walnut genotypes. Erwerbs-Obstbau, 58(1), 11-18.

Winters, R. A., Zukowski, J., Ercal, N., Matthews, R. H., \& Spitz, D. R. (1995). Analysis of glutathione, glutathione disulfide, cysteine, homocysteine, and other biological thiols by high-performance liquid chromatography following derivatization by $\mathrm{N}$-(1-pyrenyl) maleimide. Analytical Biochemistry, 227(1), 14-21. PMid:7668373. http://dx.doi.org/10.1006/abio.1995.1246.

Wojdyło, A., Oszmiański, J., \& Czemerys, R. (2007). Antioxidant activity and phenolic compounds in 32 selected herbs. Food Chemistry, 105(3), 940-949. http://dx.doi.org/10.1016/j.foodchem.2007.04.038. 